\section{Madres heroicas y padres ausentes en Ana Isabel, una niña decente por Antonia Palacios}

Rose Anna Mueller ${ }^{(1)}$

Resumen: La primera obra en prosa de Antonia Palacios (Venezuela, 1904-2001) se publicó en Buenos Aires en 1949. En 1950 la novela llegó a Venezuela, Colombia, Argentina y otros países de América Latina. En 1952 llegó a Europa: España, Portugal, Holanda y Francia. Palacios, una reconocida poeta y activista social, vivió durante la dictadura represiva de Juan Vicente Gómez (1908-1935). La novela expone hábilmente las contradicciones y complejidades del legado colonial y patriarcal de Venezuela durante su transición en una economía petrolera. La joven narradora cuestiona los estrictos roles de género y del legado dictatorial, especialmente las consecuencias para las mujeres. Palacios combina su habilidad como poeta con la capacidad de narrar las experiencias de una joven que vive en una sociedad rígidamente estructurada.

Las mujeres forman parte de una economía doméstica creando dulces, cosiendo, vendiendo leche, lavando ropa, o, como en el caso de la madre de Ana Isabel, haciendo cajas de cigarrillos y cosiendo uniformes para los soldados. Las madres de la novela deben valerse por sí mismas, mientras que los padres están ausentes o son ineficaces. El padre de Ana Isabel está enfermo y es desempleado. El padre ausente de Pepe, aparece un día y espera que su hijo sea "macho" como él. El padre de su amiga Otilia simplemente desaparece. Los padres se van y las madres y los hijos deben cuidarse de sí mismos. Mientras el nuevo orden político en Venezuela está siendo redefinido por la dictadura y el nuevo orden económico se está redefiniendo por el descubrimiento del petróleo, el viejo orden patriarcal con sus convenciones rígidas y a veces opacas que Ana Isabel cuestiona, perdura. La novel muestra la diversidad de voces femeninas y examina los roles de género.

Palabras clave: Antonia Palacios - feminismo - Venezuela - legado colonial - legado patriarchal - roles de género.

[Resúmenes en inglés y portugués en las páginas 253-254]

(1) RoseAnna Mueller is Faculty Emeritus, former coordinator of humanities and foreign languages at Columbia College Chicago. Participant in four National Endowment for the Humanities Seminars and Institutes, recipient of a Teaching/Research Fulbright Fellowship in Venezuela (2002-2003) and Colombia (2017). Book publications include Ana Isabel, A Respectable Girl (2016) and Teresa de la Parra: A Literary Life (2012). Publications and book reviews appear in The Hispanic Connection, Latin American Women Characters, A Twice-Told Tale: Reinventing the Encounter in Iberian/Iberian American 
Literature and Film, Latin America as its Literature, Women Characters in Latin American Literature, The Latin American Feminist Encyclopedia, Hispania, Letras Femeninas, and The Chicago Tribune.

La primera obra en prosa de la poeta Antonia Palacios (Venezuela, 1904-2001) se publicó en Buenos Aires en 1949. En 1950 la novela llegó a Venezuela, Colombia, Argentina y otros países de América Latina donde se convirtió en un éxito en ventas inmediato. En 1952 llegó a Europa: España, Portugal, Holanda y Francia. Su influencia e importancia creció hasta que la novela es declarada por el Ministerio de Educación de Venezuela como texto obligatorio de Segundo y Tercer año de Bachillerato (Ficciones y Aflicciones 302).

Palacios, una reconocida poeta y activista social vivió durante la dictadura represiva de Juan Vicente Gómez (1908-1935). El fin de la dictadura ha sido considerado en Venezuela como el punto de ruptura entre el pasado decimonónico y el inicio de la modernidad" (Pantín y Torres 63). La novela expone hábilmente las contradicciones y complejidades del legado colonial y patriarcal de Venezuela durante la expansión del país y la dependencia de Venezuela en una economía petrolera. Ana Isabel Alcántara, la joven narradora es una niña observadora que cuestiona los estrictos roles de género y se despierta a la realidad del legado dictatorial en que ella crece. La novela examina las confusiones para una niña de crecer en una sociedad de este en plena dictadura, especialmente las consecuencias para las mujeres.

Pero antes de analizar la novela, algunas palabras acerca de la autora. Palacios no recibió una formación académica formal. No asistió a la escuela, no pudo estudiar, no tuvo amigos importantes, no tuvo lo que ella misma llamó una "vida hacia afuera." Vivía en una Caracas donde aún se hablaba, y se continuó hablando durante años, de "gente decente" de la importancia de los "apellidos" (Ficciones y Aflicciones 291). La familia de su padre descendía directamente de Bonifacio Palacios, hermano de la madre de Simón Bolívar. Pero fue la madre de Palacios quien tuvo mucha resonancia en la vida de su hija y fue esencial para su formación. Gracias a su madre aprendió a apreciar la música y tocar el piano y hablar francés. Ella estimuló su pasión para la literatura y gracias a su madre, Palacios tuvo una vocación literaria. En una entrevista ella confesó que "Mi infancia fue terrible, porque mi padre era epiléptico y mi madre me crió en una atmosfera de ternura, pero muy miserable y la única evasión que yo tenía eta montarme en el techo, soñar e imaginarme cosas. Y empecé a escribir esas cosas creadas en mi mente, y así nació Ana Isabel. (Pantín y Torres 822). Participaba en la animación cultural y en las luchas políticas y sociales. Participó junto con su hermano, su cuñada y otros en las revueltas que se organizaban contra la dictadura. Una de estas protestas fue el movimiento estudiantil de febrero de 1928 en la Universidad Central de Venezuela en la cual los líderes estudiantiles intentaron iniciar un movimiento para liberar a Venezuela de la tiranía de Gómez. Numerosos participantes murieron o resultaron heridos. Gómez respondió cerrando las universidades y arrestando a los estudiantes, cuyos líderes fueron llamados la 
"Generación de 1928". Algunos de ellos murieron en la cárcel, y otros escaparon o fueron exiliados. En 1936 Palacios había viajado a Paris, donde siguió cursos con Piaget y María Montessori. En 1940 asistió al Segundo Congreso Venezolano del Niño como delegada de la agrupación, donde presenté una ponencia llamada "Los deberes de la maternidad" (Elena Iglesias 50). Participó en varias actividades culturales contribuyendo ponencias, discursos y artículos periodísticos por El Nacional y la revista Elite.

La novela empieza con Ana Isabel, una jovencita de ocho años jugando detrás de la reja de su casa en Caracas. Es tan pequeña que puede escapar tras los balustres. Esta novela consta de una serie de dieciséis viñetas relacionadas centradas en los espacios domésticos en la década de los 1920 en Caracas. En ese momento, la ciudad era una colección de pequeños barrios anclados alrededor de las plazas de la ciudad, plazas dominadas por la iglesia parroquial. La casa de Ana Isabel está situada en la Plaza Candelaria y su iglesia. Esta plaza se convierte en el entorno focal de una narrativa para esta "novela de formación" o bildungsroman, que explora cómo los espacios públicos y privados definen las fronteras entre los géneros, las razas y las clases. La vida "respetable" se vive dentro de las paredes y patios de las casas coloniales y las escuelas parroquiales. Estos espacios reflejan los roles de género anticuados y patriarcales que gobiernan la vida cotidiana. Dentro de este entorno, la joven narradora crece a partir de una niña perceptiva de ocho años hasta llegar a la pubertad. Ella describe sus pensamientos internos y trata de dar sentido al mundo que la rodea. Palacios combina su habilidad como poeta con su capacidad de narrar las experiencias de una joven que vive en una sociedad rígidamente estructurada y una vida monitoreada y clausurada, donde muchas de las mujeres viven una vida precaria.

El nuevo orden político en Venezuela de la década de los 1920 dio lugar a una nueva economía y su propio código de estratificación social que está en conflicto con la definición de lo que es apropiado, noble y "respetable". Los padres de Ana Isabel le cuentan come la familia es descendiente de conquistadores y tiene el escudo de armas de Alcántara para probarlo. Ana Isabel refleja “ ¿...su padre, que es más honrado que nadie acaso no pertenece a la familia más honrada de Venezuela?” (Ana Isabel 37). Pero su padre, el Doctor Alcántara, está siempre enfermo y lleva los zapatos rotos. A medida que Ana Isabel se acerca a su adolescencia lucha por ajustar sus nociones y creencias adquiridas desde su infancia hasta enfrentar las realidades de la vida. El padre de Ana Isabel está enfermo y es desempleado. Además de su enfermedad, su orgullo y el hecho de que él no tiene contacto con los que están en contacto con el poder político, lo rinde sospechoso y deprimido." - Un escudo muy limpio tenemos-repite siempre el Doctor Alcántara-. Y no poseemos dinero; prueba de que no somos ladrones ni pillos..." (Ana Isabel 76). ${ }^{1} \mathrm{La}$ relación de la joven narradora con su padre, un padre que se menciona solamente una vez por ella, es una relación negativa. "Su padre la invita a trepar sus rodillas para jugar a caballito. Pero Ana Isabel esconde el rostro para impedir que su padre la bese. Su padre tiene un aliento fuerte y metálico y unos bigotes ásperos que las rasguñan" (16). Pero hay otra razón porque la niña no quiere acercarse a su padre. "Ana Isabel se pasa la mano por la cara. ¿Porque le duela la cara? ¡Ah, sí! ¡La mano de su padre! Esa mano grande, huesuda, con enormes coyunturas. Ana Isabel se pasa la mano por la frente y se siente la piel abultada. Tal vez ha sido con la sortija. La sortija de oro ancha y pesada, con el escudo de 
los Alcántara. ¡Golpea fuerte, el escudo de los Alcántara!” (Ana Isabel 16). El escudo, que debería representar el honor de la familia, se convierte en algo que causa daño a la niña. Según Amaya Alvarado "El padre de Ana Isabel representa una autoridad que se ejerce infundiendo temor" (38).

El padre de Ana Isabel también está ausente cuando su hija se enferma. En el capítulo "El Delirio" es la madre que cuida a su hija. Es ella quien prepara el caldo y los huevos, y es ella que sugiere que la niña enferma salga al patio para tomar un poco de sol. Pero Ana Isabel todavía está muy débil "Ha sido una locura mía el dejarte salir fuera tan pronto.... Los dos caminan lentamente al cuarto, y la autora sobrelínea con ternura el amor que la madre siente para su hija. "Los brazos de la madre ciñen el menudo cuerpo con tibio y sosegado calor" (Ana Isabel 112).

El padre ausente de Pepe, el amigo de Ana Isabel, aparece en la plaza de repente y da una moneda a su hijo y espera que un día su hijo sea "macho" como él. "El hombre alejóse riendo y Pepe se quedó parado en medio de la plaza con la moneda en la mano.

—¿Quién es ese? — preguntó Ana Isabel.

-Mi papá.

¿Tu papá? ¿Y por qué no vive contigo?

—Gua, allá él. ¿Qué voy a sabé yo? Alla él. Alla él...”

El padre de Pepe responde con orgullo, "Dios me lo bendiga. Guá, va a sé un hombre...Y como que va a sé macho como yo ... y el hombre miró con malicia a Ana Isabel "(Ana Isabel 91).

El padre de su amiga Otilia simplemente desaparece. "Más abajo queda la casa de Otilia, pero Otilia no vive allí. Su padre se marchó un buen día y la madre de Otilia lo estuvo esperando muchos meses pero nunca regresó. ¿Adónde se iría el padre de Otilia? Tal vez a los Llanos ..." (Ana Isabel 121). Pero este cambio atrae a otras mujeres que subsisten con su pequeña empresa. "Ahora en la casa de Otilia viven unas viejas señoritas solteronas que hacen dulce y los vende Consuela la isleña" (Ana Isabel 121). La madre de Otilia también tiene que encontrar empleo. "La madre de Otilia se empleó en una casa de sirvienta "(Ana Isabel 121). Aquí hay un excelente ejemplo del modelo económico que permite a las mujeres ganarse la vida. Las viejas señoritas producen los dulces que son distribuidos por otra mujer, mientras que la madre de Otilia está obligada a ganarse la vida después que su esposo deja a ella y a su hija sin apoyo financiero. Es solo un ejemplo de muchas de las circunstancias describidlas en la novela que explica como la ausencia de los padres desempleados o ausentes causa una vida difícil paras las mujeres, sean ellas casadas, solteronas o viudas. Dos otras representaciones de hombres ausentes son los parientes de Ana Isabel. El abuelo Kraus muerto, pero amado por Ana Isabel, fue exiliado por sus afirmaciones políticas y perdió todos sus bienes. El abuelo maternal Kraus era dueño de una próspera hacienda de café. "Pero los buenos tiempos pasaron pronto. Revivieron los tradicionales atropellos políticos venezolanos... El abuelo fue confinado a Curazao y perdió sus tierras" (Ana Isabel 52). La toma gubernamental de la hacienda es especialmente dura para la familia ya que la exportación de café era la empresa principal de Venezuela antes del descubrimiento del petróleo. 
El tío paternal Marcelino es rico y desagradable y no tiene interés ni en su familia ni en su país. "Ana Isabel y Jaime no ven casi nunca al tío Marcelino. El tío Marcelino es un viejito seco y apergaminado, con gorra de seda y pantuflas de cuero. Tiene mucho dinero. Pero no es simpático el tío Marcelino. Nunca les ha dicho un cariño. "No tiene niños el tío Marcelino, ni esposa tampoco. Ha vivido largo tiempo en Paris y habla francés (Ana Isabel 30). Con los padres ausentes o desempleados, toca a las mujeres ganar dinero para sus familias. Ellas forman una economía doméstica cocinando y vendiendo dulces, cosiendo, vendiendo leche, lavando ropa, o, como en el caso de la madre de Ana Isabel, creando cajas de cigarrillos y cosiendo uniformes para los soldados. Las madres de la novela deben valerse por sí mismas, mientras que los padres están ausentes o son ineficaces. La madre de Ana Isabel lucha por mantener la decencia de su casa. Hace cajetillas de cigarro. En muchas maneras es obligada de sustituir al padre. Hace un esfuerzo para mantener las relaciones con la gente que ofrecen buenos modelos para sus hijos. La señora Alcántara debe trabajar en varias labores para mantener a la familia. Cuando decide comprar dos vacas para vender leche y ganar un poco más dinero para sostener a su familia, incorpora el corralón, y ahora Ana Isabel puede observar a Elisa, la niña isleña trabajadora. “...una chica de unos doce años, que lavaba y planchaba a ropa a las señoras de la vecindad. Ana Isabel la miraba torcer entre sus manos las grandes sábanas blancas, ...Al secarse, ásperas y duras, Elisa las desprendía de las cuerdas una a una y las rociaba con agua fresca antes de aplancharlas" (Ana Isabel 80). A causa de los padres ausentes, los niños se ven obligados a ayudar con su labor. La misma señora Alcántara alista a sus hijos en el montaje de cajas de cigarrillos. Al principio es un juego, pero en los días soleados, cuando Ana Isabel y su hermano Jaime se ven obligados a ayudar a su madre, miran con tristeza por la ventana y desean poder estar jugando en la plaza con sus amigos.

El desempleo o la ausencia de los padres es responsable para la pobreza que aflige a Ana Isabel y ella se da cuenta de la desigualdad económica en la sociedad venezolana. Después de encontrarse en la plaza con Pepe y su padre recién llegado, Ana Isabel contempla, "Y Ana Isabel piensa que los pobres, los pobres de verdad, no como ella, como Ana Isabel, sino los pobres como Perico y Carmencita, como Eusebio, Pepe el monaguillo, y Petrica, la hija de Domitila, y Eladio, el que vive quebrada abajo...los pobres de verdad verdad, casi nunca tienen papá. Petrica, la hija de Domitila, no tiene papá, ni Eladio tampoco, ni Eusebio, ni Encarnación, el hijo de Concha. Los pobres no tienen papá; solo tienen mamá. La mamá que lava, que pila, que hace arepas, que carga agua... ¿Por qué los pobres no tienen papá? (92). Es claro que los padres se van y las madres y los hijos deben cuidarse por sí mismos. Mientras que el nuevo orden político en Venezuela está siendo redefinido por la dictadura y el nuevo orden económico se está redefiniendo por el descubrimiento del petróleo, el viejo orden patriarcal con sus convenciones rígidas y a veces opacas que Ana Isabel cuestiona, perdura ${ }^{2}$.

La novela refleja la diversidad de voces femeninas, de las labores honrables cumplidos por mujeres heroicas. Representa la reapropiación de géneros subalternos y las historias mínimas y cotidianas en las vidas de las mujeres. Antes eran voces aisladas, calladas, sin representación, voces que hablaban al margen de la historia. Palacios quiso incorporar la presencia de la mujer activa. Cuando la novela empieza, la joven Ana Isabel oscila entre dos mundos: plaza y escuela, pero crece en una joven que quiere narrarse a si misma y su 
mundo de mujeres activas. La niña precoz encuentra su voz., un personaje con un claro sentido de pertenencia.

La novela describe la vida dentro de las paredes y los patios de una casa antes de la llegada de los edificios altos que dominan el horizonte actual de Caracas. Se trataba de casas coloniales con patios interiores, con techos de tejas rojas y aleros colgantes. Empieza con la observación, "Ana Isabel siempre ha vivido frente una plaza. Esas plazas caraqueñas con su ambiente aldeano, rodeadas de casa, que se apretujan las unas contra las otras. Casas iguales, con aleros de tejas y ventanas con balaustres" (Ana Isabel 9). Estas casas eran fortalezas cerradas, protegiendo y a la familia. Ana Isabel no está segura de las circunstancias económicas de su familia; en comparación con los pobres que viven en los barrios, ella no es tan pobre como ellos. Pero comparándose con los amigos y parientes ricos con sus conexiones gubernamentales, ella se considera pobre.

A medida que Ana Isabel se acerca a su adolescencia y juventud, lucha por ajustar sus nociones y creencias adquiridas en su infancia a las realidades de la vida. Ana Isabel reflexiona y se pregunta al entrar en contacto con los diversos miembros de su comunidad: el zapatero, el maestro, el sacerdote, el farmacéutico y el mundo de sus abuelos muy diferentes. Los personajes cobran vida a través de las descripciones poéticas destiladas del narrador y su evocación de su habla, ropa y manierismos.

A través de las reflexiones de Ana Isabel Palacios examina las actitudes raciales de una Venezuela que estaba pasando de una economía agraria rural a un país petrolero. Al mismo tiempo la novela nos muestra la evolución psicológica y moral de una niña nacida en una familia de alcurnia venida a menos. Ana Isabel misma funciona como heroína en sus atentos de homologar los sujetos subalternos, es decir, los niños negros y los niños pobres representados por el negro Eusebio y Carmencita, la hija del carbonero. Los dos niños son símbolos de las tensiones sociales que golpean a Ana Isabel. Ella representa una niña que no acepta una sociedad injusta. Propone una propuesta más democrática de inclusión social y económica. Soñando por encima del techo, Ana Isabel contempla y ofrece una solución. "¡Si todo el mundo fuese rico, se acabarían los pobres! Si los pobres robasen, se acabarían los pobres. ¡Todo el mundo tendría una casa grande!” (Ana Isabel 38). No está de acuerdo con la resignación de Gregoria, la domestica negra acostumbrada con su estatus-Los pobres son pá aguantá. Sufrí y aguantá... (Ana Isabel 38).

La señora Ferbeau representa a la trabajadora extranjera que cambiará la cara de la sociedad venezolana como los chinos que montan lavanderías y otras empresas que reflejan los cambios de la modernidad. La señora Ferbeau, la madre de Justina, amigo de Ana Isabel, es catalana, y dueña de una peluquería y una tienda donde vende "cosas lindas" y con este ejemplo Ana Isabel se da cuenta que hay otros oficios y cargos para las mujeres además de los labores domésticos, los trabajos tradicionales, los "labores de señoras". "Las mujeres participan en un proceso que trata de crear un mundo más justo, donde haya ascenso social, progreso y posibilidades de desarrollo para la mujer" (Amaya Alvarado 46). "La Señora Ferbau estaba siempre detrás del mostrador, con el cabello peinado hacia arriba y un espeso mono en medio de la cabeza. Ella misma hacía de vendedora y apuntaba en un grueso libro, las cuentas del día" (Ana Isabel 31). La dueña de su propio negocio ofrece un contraste con las industriosas que trabajan con sus manos, haciendo pan y leche y vendiendo sus productos por las calles. 
La autora nos ofrece un desfile de heroínas de la vida diaria cuyos trabajos son necesarios para la vida de sus proprias familias y para la comunidad. A través de la descripción de estos personajes la autora nos ofrece sus comentarios sobre la sociedad, el prejuicio racial y la pobreza en que viven las mujeres en la Venezuela atrapada en sus valores coloniales. En una Venezuela en cuyos los cambios económicos beneficiaron solamente a los asociados y loa amigos del dictador. “..., the true beneficiaries of the petroleum industry bonanza were Gómez and his associates and cronies. (Tarver and Frederick 80).

La maestra de Ana Isabel es un ejemplo de otra mujer empleada. "En la escuela solo sabía de su voz un tanto velada y monótona. De sus manos que sostenían la tiza, el libro, la regla. Siempre vestida de alto cuello y largas mangas" (Ana Isabel 69). Pero durante la excursión al río, mientras la maestra se baña con sus alumnos, "Ana Isabel no reconocía a la señorita. ¡Qué brazos tan blancos surcados de venas azules! ¡Y qué hermoso pelo! ¿Acaso es bonita la señorita?" (Ana Isabel 69). La joven estudiante se da cuenta de que su maestra es más que una señorita aburrida.

Gregoria representa la doméstica destinada a trabajar para la misma familia toda su vida. Ana Isabel la contempla, "Ella no quiere parecerse a Gregoria, con esos ojos llorosos, enrojecidos por el humo, y con esas manos... Oh, ¡las manos de Gregoria! Con unas saltadas y venas gruesotas y aquel dedo negro y cabezón, por culpa de un panadizo del tanto lavar...(Ana Isabel 20). También hay los ejemplos de "La negra Domitila, la misma que llega el pan de arepa todos los días a su casa y Elvira que vende el alfondoque por las calles, atravesando la plaza con su grito largo" (Ana Isabel 21). Poco a poco Ana Isabel se da cuenta que mientras estas mujeres forman el eje de la sociedad diaria venezolana, cuando sale de su casa, otros ejemplos de mujeres profesionales y empresarias se presen$\tan$ ante sus ojos.

Otras heroínas son las mujeres que arreglan el funeral de Francisco el zapatero, que no tenía ni mujer ni hijos ni hermanos. Allí en la sala pequeña donde yacía Francisco están Domitila y Amalia y Concha, la que hace cachapas y la tía de Eladio y Carmencita. "Las mujeres hablaban de emplastos y de hierbas y de Francisco, que no se había curado. Pepe había traído ron de la bodega y los hombres habían lanzado palabrotas escupiendo por el colmillo" (Ana Isabel 124). La escena ofrece un contraste tras la actitud y el esfuerzo de las mujeres y los hombres durante el velatorio de un hombre sin familia. La comunidad de mujeres ha arreglado todo para que Francisco puede tener un entierro digno, mientras que los hombres se emborrachan, gracias al ron de Pepe.

En el último capítulo de la obra, "Ana Isabel se ha quedado al otro lado de la reja," la autora nos presenta una adolescente que se siente atrapada por su estatus como mujer, que ahora como le aconseja su madre después de su primera menstruación-"Ya eres una señorita-le había dicho su madre-Ahora tienes que tener mucho juicio." (Ana Isabel 120). La autora deja al lector con la pregunta si es posible para Ana Isabel salir otra vez por la plaza y convertirse en la heroína de su propria vida.

Sin predicar ni levantar polémica Palacios logra describir la situación económica con la que las mujeres tenían que luchar y cómo se dedicaban a una economía doméstica, una red de mujeres que producían, distribuían y vendían sus productos y servicios en la ausencia de hombres productivos. Demuestra la industria y autonomía de las mujeres que viven en un mundo de hombres ausentes. En Calicanto, el nombre de su casa, en 1978, 
Antonia Palacios estableció un taller literario importante en la formación de nuevos escritores, y para abrir nuevos diálogos y fomentar nuevas maneras de escribir la identidad venezolana.

Según el hijo de la escritora, Fernán Frías Palacios, "La obra de Antonia Palacios es buen conocida tanto en Venezuela como en el ámbito literario latinoamericano e internacional. Su obra ha sido objecto de reconocimiento por parte de destacados autores de la talla de Uslar Pietri. Juan Liscano, Oswaldo Trejo, Humberto Díaz Casanueva, Miguel Otero Silba, Isaac Pardo y otros que sería tedioso enumerar" (Obras Completas, prólogo). Su hijo confesó el amor y profunda admiración por su madre. "Y es que ella no se limitó a escribir, sino que dejó plasmada su influencia en diversos aspectos que denotan su preocupación por el rol de la mujer en el seno de la sociedad. Así fue fundadora de la Agrupación Cultural Femenina en el año 1939, presidenta del Primer Congreso Venezolano de Mujeres y creadora del Taller Calicanto, crisol e escritores y poetas en el que se favorecía el encuentro de jóvenes escritores que luego se incorporarían exitosamente a nuestra literatura. Todo esto refleja su lucha por denostar con hechos concretos, el inmenso valor de la mujer en la sociedad actual, especialmente en el campo de la creación" (prólogo). La novela nos presenta heroínas ficticias creadas por su autora, ella misma es una heroína en carne y hueso que luchó por los derechos de la mujer. La novela refleja claramente la vida de la autora, y su visión para su creación, el personaje Ana Isabel, con el "Objeto del deseo de la intelectual femenina, que desea salir libremente a la militancia política, el ejercicio periodístico y por supuesto a la práctica de la escritura" (Amaya Alvarado 53). La novela ofrece una propuesta para ejercer la feminidad en un modo más progresista que puede liberar a la adolescente que queda detrás de la reja.

\section{Notas}

1. "Political life in nineteenth-century Latin America was characterized by competing networks of friends and followers, the so-called patronazgo structures" (Tarver and Frederick 74).

2. "For most Venezuelans, the petroleum era did not bring with it additional jobs, increased wages or an improvement in their standard of living" (Tarver and Frederick 80).

\section{Bibliografía}

Amaya Alvarado, Carolina Ysabel (2010). Perforando el vacío: relectura y resignificación de la escritura poética de Antonia Palacios. Caracas: Universidad Católica Andrés Bello. Iglesias, Elena (1979). Antonia Palacios: esa columna en vilo: Caracas: Universidad Católica Andrés Bello.

Liscano, Juan (1989). "Prólogo" Ana Isabel una niña decente. Caracas: Monte Ávila Editores. (1984). Panorama de la literatura venezolana actual. Caracas: Alfadil. 
Ludmer, Josefina (1985). "Las tretas del débil" La sartén por el mango. Puerto Rico: Ediciones Huracán.

Mueller, RoseAnna. Trad. (2016). Ana Isabel, a respectable girl. Antonia Palacios. Montreal: Universitas Press.

Palacios, Antonia (2002). Obras Completas. Caracas: Calicanto.

(1994). Ficciones y Aflicciones. Caracas: Biblioteca Ayacucho.

Pantín, Yolanda and Ana Teresa Torres (2003). El hilo de la voz: antología crítica de escritoras venezolanas del siglo XX. Caracas: Fundación Polar.

Rivas, Luz Marina (2003). "Ellas tomaron la palabra: un siglo y algo más de las narradoras venezolanas" Revista venezolana de estudios para la mujer. Vol.8, No 21, Caracas, julio-diciembre.

Tarver, H. Michael and Julia C. Frederick (2006). The History of Venezuela. New York: Palgrave McMillan.

\section{Heroic mothers and fathers absent in Ana Isabel, a girl decent by Antonia Palacios}

Abstract: Antonia Palacios's (Venezuela, 1904-2001), first prose work was published in Buenos Aires in 1949. In 1950 the novel reached Venezuela, Colombia, Argentina and other Latin American countries. In 1952 it arrived in Europe: Spain, Portugal, Holland and France. Palacios, a renowned poet and social activist lived during the repressive dictatorship of Juan Vicente Gómez (1908-1935). The novel deftly exposes the contradictions and complexities of Venezuela's colonial and patriarchal legacy during the country's expansion and Venezuela's transition to an oil economy. The young narrator questions the strict gender roles and awakens to the reality of the dictatorial legacy and its consequences for women. Palacios combines her ability as a poet with the ability to narrate the experiences of a young woman living in a rigidly structured society with her life monitored and enclosed.

Women are part of a domestic economy creating sweets, sewing, selling milk, washing clothes, or, as in the case of Ana Isabel's mother, making boxes of cigarettes and sewing uniforms for soldiers. The mothers of the novel must fend for themselves, while the fathers are absent or ineffective. Ana Isabel's father is sick and unemployed. Pepe's absent father, Ana Isabel's friend, shows up one day and expects his son to be "male" like him. Her friend Otilia's father simply disappears. Fathers leave and mothers and children must take care of themselves. While the new political order in Venezuela is being redefined by dictatorship and the new economic order is being redefined by the discovery of oil, the old patriarchal order with its rigid and sometimes opaque conventions that Ana Isabel questions endures. The novel displays a diversity of female voices while it reexamines gender roles.

Keywords: Antonia Palacios - feminism - Venezuela - colonial legacy - patriarchal legacy - gender roles. 


\section{Mães e pais heróicos ausente em Ana Isabel, uma menina decente por Antonia Palacios}

Resumo: A primeira obra em prosa de Antonia Palacios (Venezuela, 1904-2001) foi publicada em Buenos Aires em 1949. Em 1950, o romance chegou à Venezuela, Colômbia, Argentina e outros países da América Latina. Em 1952, ele chegou à Europa: Espanha, Portugal, Holanda e França. Palacios, renomada poeta e ativista social, viveu durante a ditadura repressiva de Juan Vicente Gómez (1908-1935). O romance expõe habilmente as contradições e complexidades do legado colonial e patriarcal da Venezuela durante sua transição para a economia do petróleo. O jovem narrador questiona os estritos papéis de gênero e o legado ditatorial, especialmente as consequências para as mulheres. Palacios combina sua habilidade como poeta com a capacidade de narrar as experiências de uma jovem que vive em uma sociedade rigidamente estruturada.

As mulheres fazem parte de uma economia doméstica criando doces, costurando, vendendo leite, lavando roupas ou, como no caso da mãe de Ana Isabel, fazendo caixas de cigarros e uniformes de costura para os soldados. As mães do romance devem cuidar de si mesmas, enquanto os pais estão ausentes ou são ineficazes. O pai de Ana Isabel está doente e desempregado. O pai ausente de Pepe aparece um dia e espera que seu filho seja "macho" como ele. O pai de sua amiga Otilia simplesmente desaparece. Pais saem e mães e filhos devem cuidar de si mesmos. Enquanto a nova ordem política na Venezuela está sendo redefinida pela ditadura e a nova ordem econômica está sendo redefinida pela descoberta do petróleo, a velha ordem patriarcal com suas convenções rígidas e às vezes opacas que Ana Isabel questiona. $\mathrm{O}$ romance mostra a diversidade de vozes femininas e examina os papéis de gênero.

Palavras-chave: Antonia Palacios - feminismo - Venezuela - legado colonial - legado patriarchal - papéis de gênero.

[Las traducciones de los abstracts fueron supervisadas por el autor de cada artículo] 